\title{
チタン系真空材料の表面キャラクタリゼーション
}

宗山 悦博*1 竹田 将利*1 . 國重 敦弘*1 $\cdot$ 中川 浜三*1 $\cdot$ 白水 啓太 ${ }^{* 1}$

二井 裕之 $* 1 \cdot$ 栗巣 普揮 $* 2 \cdot$ 山本 節夫 $* 2 \cdot$ 松浦 満 $* 2$

\section{Characterization of the Surface Oxide Layer Formed on a Titanium Alloy Material for Ultrahigh Vacuum}

\author{
Etsuhiro MUNEYAMA*1, Masatoshi TAKEDA*1, Atsuhiro KUNISHIGE*1, \\ Hamazou NAKAGAWA*1, Keita SHIROUZU*1, Hiroyuki NII*1, \\ Hiroki KURISU*2, Setsuo YAMAMOTO*2 and Mitsuru MATSUURA*2 \\ *1UBE Scientific Analysis Laboratory, Inc, 1978-5 Kogushi, Ube, Yamaguchi 755-8633, Japan \\ *2Department of Advanced Science and Engineering, Faculty of Engineering, Yamaguchi University,
} Ube Yamaguchi 755-8611 Japan

(Received May 12, 2006, Accepted October 14, 2006)

\begin{abstract}
The surface oxide layer of a titanium alloy treated by mechanochemical polishing (MCP) was characterized using a scanning electron microscope (SEM), transmission electron microscope (TEM), atomic force microscope (AFM), X-ray photoelectoron spectoroscopy (XPS), auger electoron spectoroscopy (AES) and secondary ion mass spectrometry (SIMS). The results showed that surface oxide layer was amorphous titanium oxide and had about $5 \mathrm{~nm}$ thickness. At the interface between surface oxide layer and substrate, there was a region of high hydrogen concentration. In the same region, the Ti-F chemical component was found. It seems that this interface layer acts as a barrier for the bulk hydrogen diffusion, and gives low hydrogen concentration at the surface layer resulting in the low outgassing property in the titanium materials.
\end{abstract}

\section{1. はじめに}

半導体材料や機能性材料, カーボンナノチューブに代表さ れるナノテク材料などの先端材料の研究分野では, 材料の評 価のため多くの分析装置，特に電子顕微鏡や表面分析装置に よる様々な分析評価が必須となっている。これらの分析装置 はいずれも $10^{-6} \mathrm{~Pa}$ 以下の圧力に到達する超高真空機器であ り，材料の表面数原子層領域の分析評価に用いられるが，分 析の妨害となる材料の表面污染や表面変質を最小にするため, $10^{-6} \mathrm{~Pa}$ 以下のさらに低い圧力が求められるようになってき た.

真空装置の到達圧力を低減するためには, 装置を構成する 材料からの放出ガスを極限までに抑える必要がある．最近， 新たな真空材料としてチタンが注目されるようになり，その 真空特性を調べる研究が進められているが, 真空性能の向上 には特に表面処理が重要であることが報告されている1-5).

筆者らは, メカノケミカル研磨 (MCP) 処理で真空特性 の顕著な向上が認められる高強度低合金チタン $(\mathrm{KS} 100$ : 神戸製鋼所製) について, MCP 処理に伴う表面の状態変化 を調ベ，表面に形成される酸化膜のキャラクタリゼーション を行ったので，その結果について記述する.

\section{2. 実験方法}

純チタンは軽量・高強度・小熱膨張率・完全非磁性・高耐 熱性などの特徵を持っているが，チタン合金 KS100は Ti マ

\footnotetext{
* 平成17年12月16日 日本真空協会中国研究例会で発表

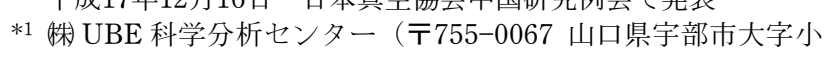
串1978-5)

*2 山口大学工学部（干755-8611 山口県宇部市常盤台 2-16-1）
}

トリックスに $\mathrm{O}, \mathrm{Fe}$ をそれぞれ $0.35 \mathrm{wt} . \%$ 含む組成で, 純チ タンに比べ高い硬度を有している. 分析試料は未処理ならび に MCP 処理した高強度低合金チタン板（サイズ：10 mm× $\left.10 \mathrm{~mm} \times 1 \mathrm{~mm}^{\mathrm{t}}\right)$ を準備し, 走査型電子顕微鏡 $(\mathrm{SEM})$, 透 過型電子顕微鏡 (TEM), 原子間力顕微鏡 $(\mathrm{AFM}), \mathrm{X}$ 線回 折 $(\mathrm{XRD})$, オージェ電子分光 $(\mathrm{AES}), \mathrm{X}$ 線光電子分光 (XPS), 二次イオン質量分析計 (SIMS), 飛行時間型二次 イオン質量分析計（TOF-SIMS）などを用いて表面のキャ ラクタリゼーションを行った.

\section{3. 表面のキャラクタリゼーション}

\section{1 表面形状}

高強度低合金チタンの SEM ならびに AFM の結果を Fig. 1 に示す. 未処理品の表面粗さは Ra $100 \mathrm{~nm}$ 程度であり, サブミクロンの凹凸が全面に見られるが，MCP 処理品では Ra $1 \mathrm{~nm}$ 程度で, 表面凹凸が除去された鏡面仕上げになっ ていることが分かる. しかし, 表面粗さによる表面積増加率 (SAD) は MCP 処理品で $0.1 \%$ 程度であり, 未処理品でも 5 \%程度であることから, 表面積については両者で大きな相違 は無いものと考えられる.

\section{2 表面組成・污染}

高強度低合金チタンのオージェスペクトルをFig. 2 に示 す. 未処理品, MCP 処理品ともに表面には, Ti, O, C が強

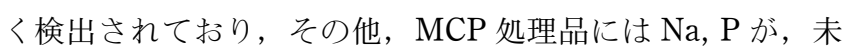
処理品には Fe が僅かに認められる。これより, 表面のチタ ンは酸化されているものと考えられ，同時に測定したXPS の結果からもチタンは $\mathrm{TiO}_{2}$ の状態であることが分かった。 表面に検出されたCは有機物污染と考えられ， $\mathrm{Na}, \mathrm{P}$ は $\mathrm{MCP}$ 処理の残留成分によるものと考えられる. 

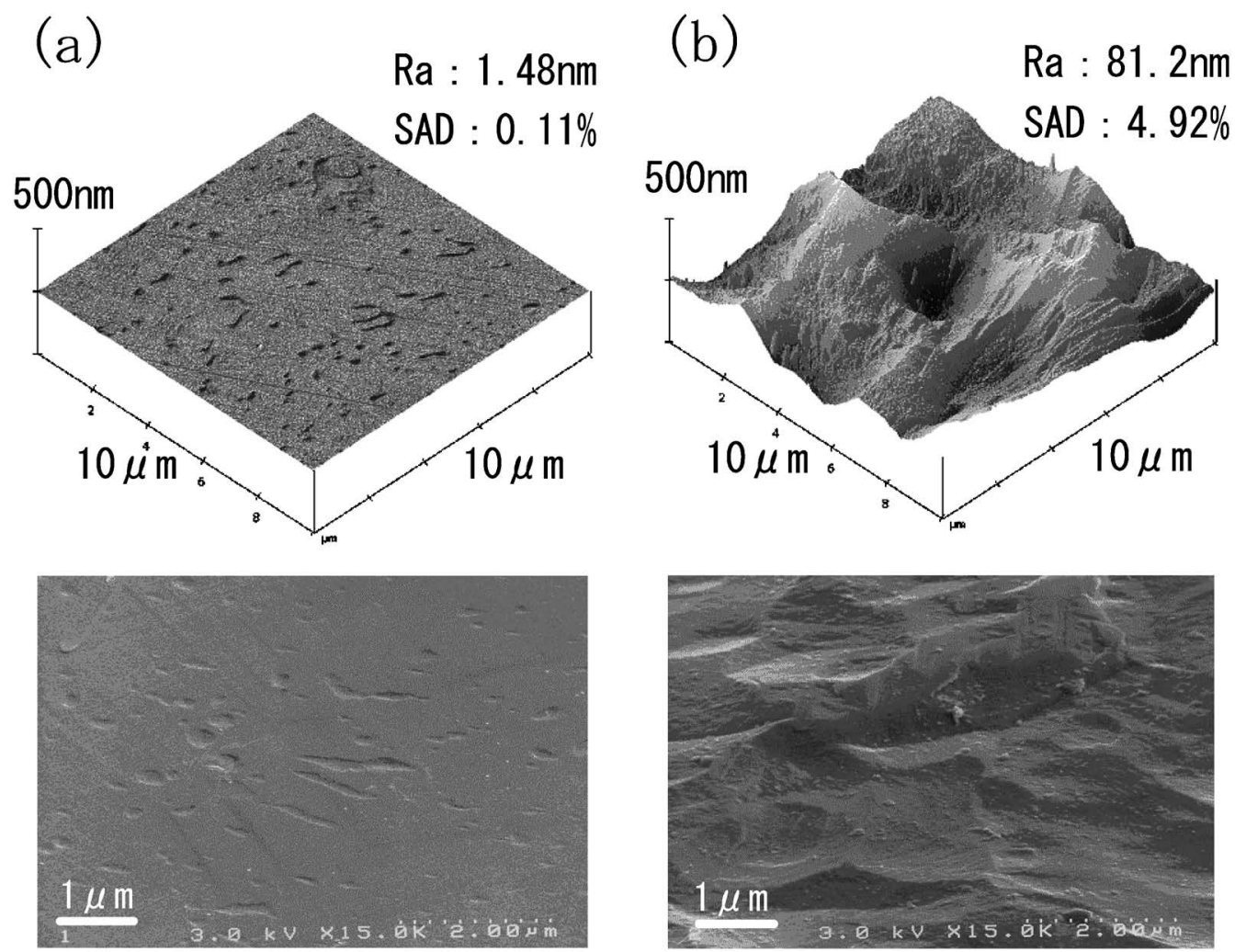

Fig. 1 SEM and AFM micrographs of the titanium alloy: (a) MCP treated, (b) untreated.

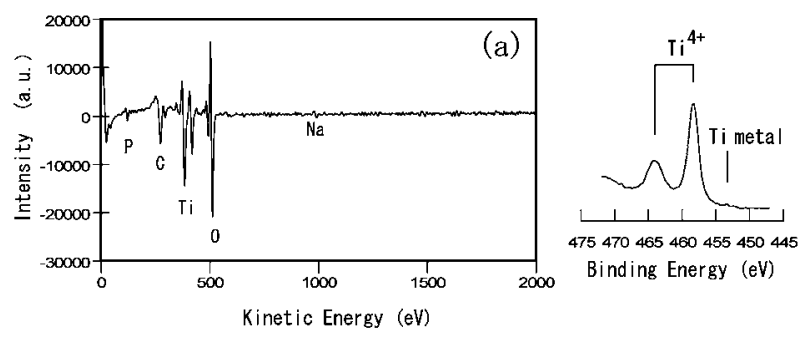

り，これは材料内部に固溶している水素原子の拡散放出によ るものと考えられている6 . 材料の表面処理による表面酸化 層の形成が水素ガス放出の低減に大きく寄与していると考え られるので, 材料中の水素に注目し, SIMS 分析を行った.

最初に高強度低合金チタンの定性分析を行ったところ，チ タンや酸素以外にフッ素が強く検出されることが分かった. このフッ素は高強度低合金チタンの製造工程（酸洗浄や MCP 処理プロセス）で導入されたものと考えられる. そこ で, SIMSによるフッ素, 水素, 酸素のデプスプロファイル 測定を行い, その結果をFig. 4 に示す. 図中に水素の 2 次 イオン像（元素マッピング）の結果も併せて示した.

フッ素, 酸素は表面層に非常に強く検出されたが, 試料間 では大きな違いは見られなかった。 水素は, 試料間で表面層 近傍でのプロファイルに違いが見られ, 未処理品の方が内部 側で水素が多く存在しているものと考えられた. また, 水素 は均一分布ではなく, 粒界程度の大きさの偏析が認められ た.これより, チタン材料内での水素の挙動は粒子の結晶方 位に強く影響されているものと推察される.

試料の表面層について, さらに詳細な情報を得るため,

\section{3 表面膜の構造 · 組成}

高強度低合金チタンの断面 TEM 写真を Fig. 3 に示す. 図中にナノビーム電子線回折像 (NBD 像) も併せて示した.

断面 TEM 写真 · NBD 像より, 表面に見られる層は非晶 質の酸化チタンであり，その厚さは $\mathrm{MCP}$ 処理品で約 5 $\mathrm{nm}$, 未処理品で約 $8 \mathrm{~nm}$ と観察された.

\section{4 表面膜の深さ方向の分析}

一般に，真空ベーキングが十分に施され，超高真空領域に 到達した場合の真空材料からの放出ガスの主成分は水素であ TOF-SIMS を用いてポジティブィオン種 $\left(\mathrm{H}^{+}, \mathrm{OH}^{+}\right.$, $\left.\mathrm{TiH}^{+}, \mathrm{TiO}^{+}, \mathrm{TiF}^{+}\right)$のデプスプロファイル測定を行った. その結果を Fig. 5 に示す.

$\mathrm{OH}^{+}, \mathrm{TiH}^{+}, \mathrm{TiO}^{+}$のデプスプロファイルは $\mathrm{MCP}$ 処理 品, 未処理品間で大きな違いは見られないが, $\mathrm{H}^{+}$と $\mathrm{TiF}^{+}$ については顕著な違いが見られ，リニア表示（Fig. 6, 7) することで, $\mathrm{MCP}$ 処理品の表面層と基板との界面近傍で $\mathrm{H}^{+}$と $\mathrm{TiF}^{+}$が極大分布していることが分かる。この領域は 

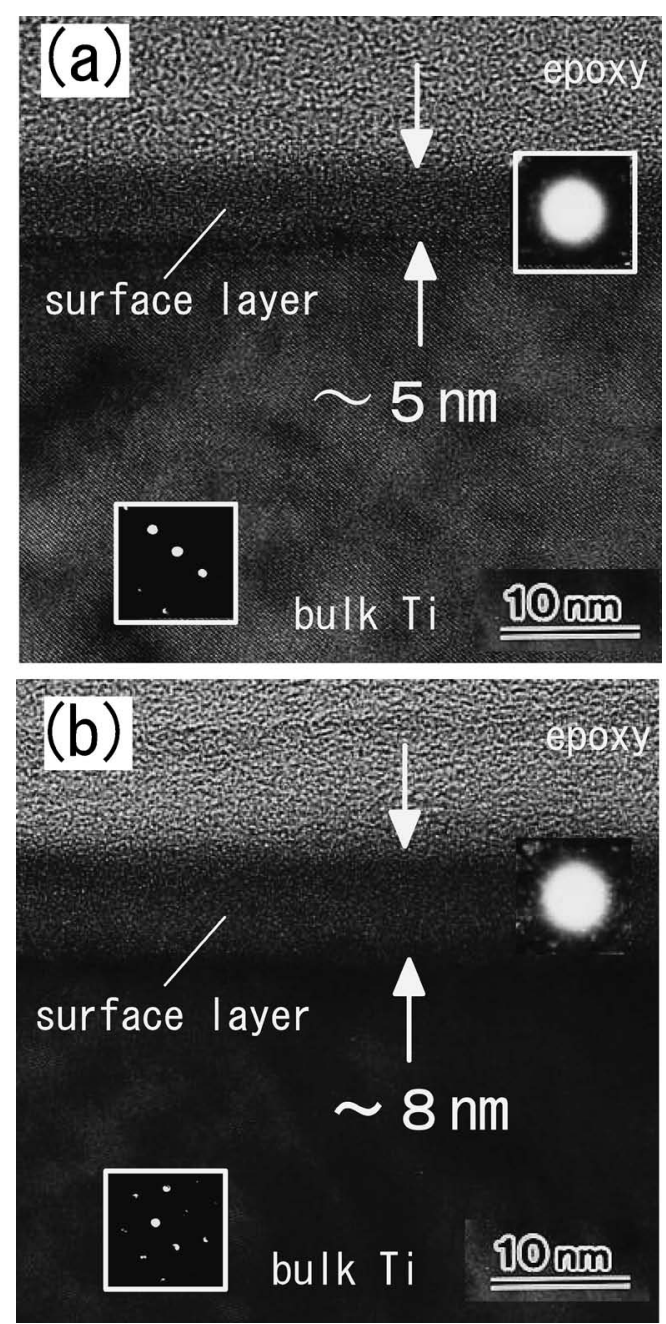

Fig. 3 Cross-sectional TEM micrographs and diffraction patterns of the titanium alloy: (a) MCP treated, (b) untreated.
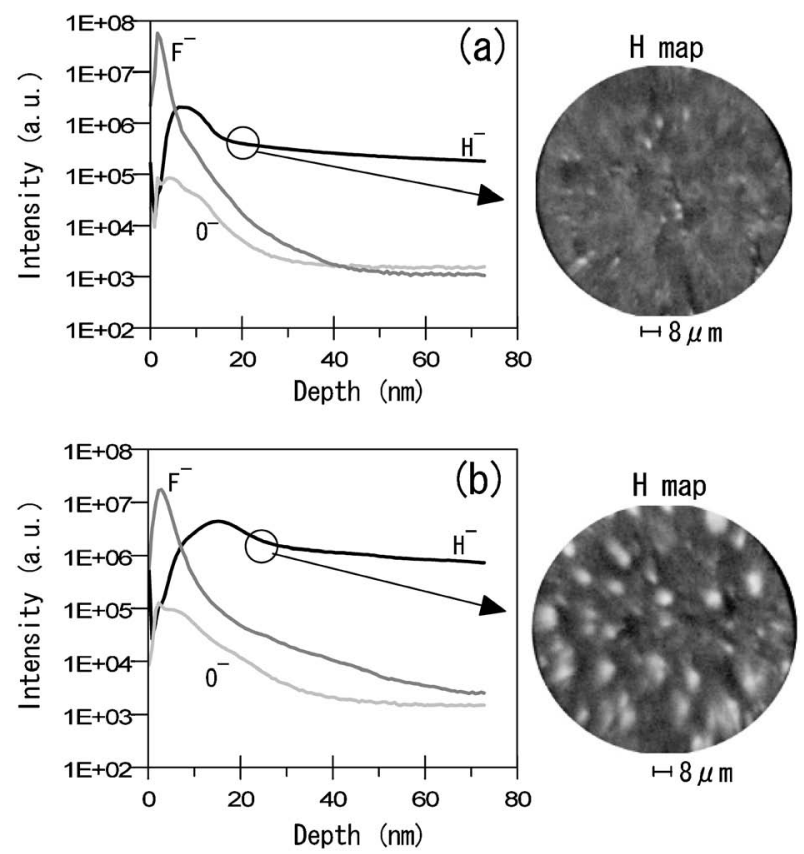

Fig. 4 SIMS depth profiles of $\mathrm{H}^{-}, \mathrm{O}^{-}, \mathrm{F}^{-}$and secondary ion images of $\mathrm{H}^{-}$in the titanium alloy: (a) MCP treated, (b) untreated.
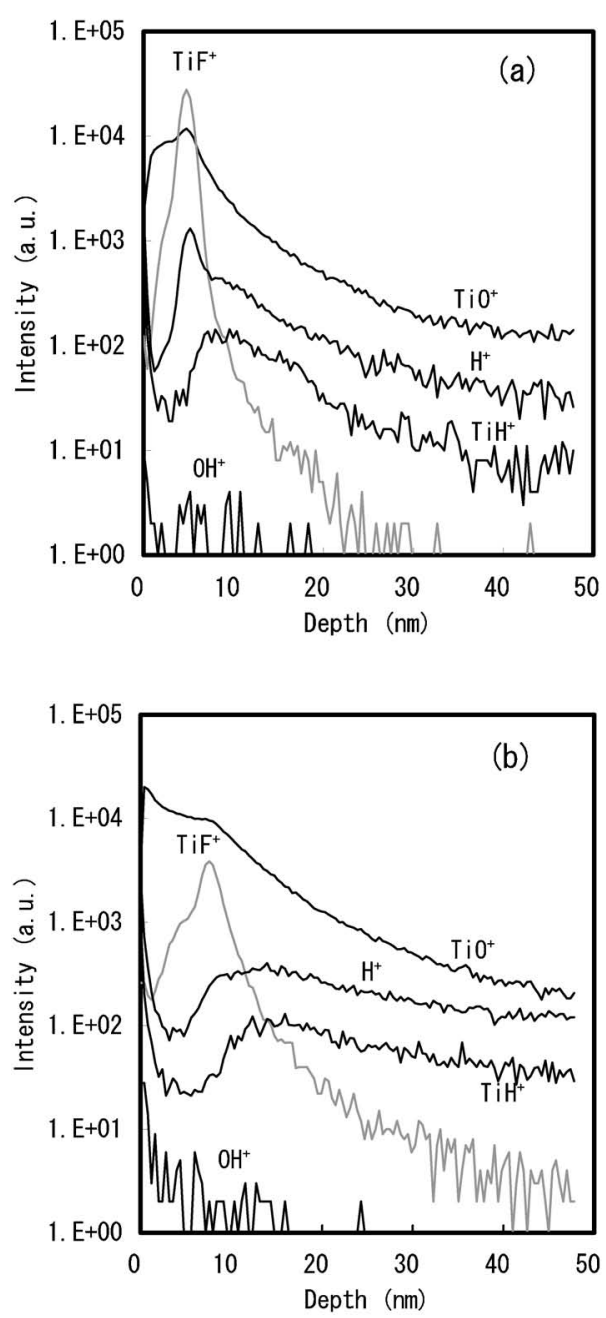

Fig. 5 TOF-SIMS depth profiles of $\mathrm{H}^{+}, \mathrm{OH}^{+}, \mathrm{TiO}^{+}, \mathrm{TiH}^{+}$ and $\mathrm{TiF}^{+}$in the titanium alloy: (a) MCP treated, (b) untreated.

1〜2 nm 厚の非常に薄い領域であり, 以後, この領域を界面 層と表記する.

$\mathrm{MCP}$ 処理品の水素は表面膜内には少なく, この界面層に 局在していることから，MCP 処理により界面層に水素を含 む化合物や欠陥が形成されるものと考光られる． $\mathrm{TiF}^{+}$も $\mathrm{H}^{+}$と同様な分布を示しており, さらにXPS 測定によりフ ッ素はフッ化物の状態と考えられることから，この界面層に は, チタンとフッ素が結合した成分の存在が示唆される。 ま た界面層より深い領域でも水素は分布して抢り，それは $\mathrm{TiH}^{+}$の分布に対応していることから，金属格子内の水素に 由来すると考えられる．すなわち水素の分布が境界層で大き く, 表面膜で小さいことから, 真空排気によりチタンでは表 面近傍に扔いて水素の低濃度状態が実現され，これが低ガス 放出を与えるものと考えられる。しかしながら，このチタン のガス放出機構については, 界面層やさらに深部に溶存した 水素の拡散や表面近傍の水素の挙動について, さらなる研究 が必要である。

\section{4. まとめ}

高強度低合金チタン（KS100：神戸製鋼所製）について, 

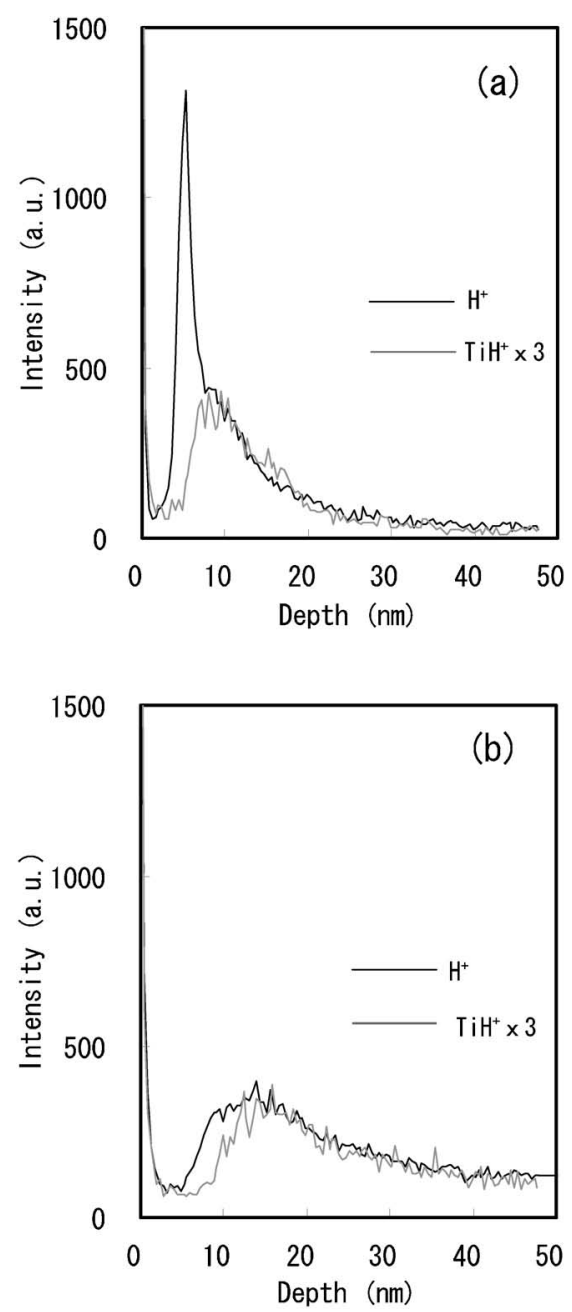

Fig. 6 Overlay of TOF-SIMS depth profiles of $\mathrm{H}^{+}$and $\mathrm{TiH}^{+}$ in the titanium alloy: (a) MCP treated, (b) untreated.

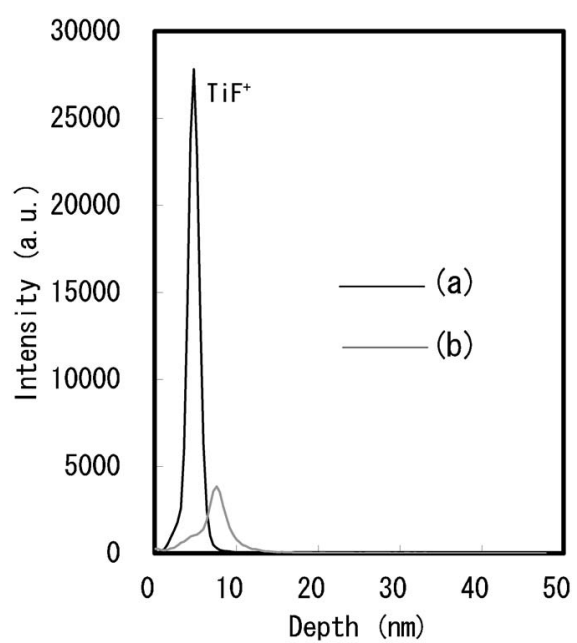

Fig. 7 Overlay of TOF-SIMS depth profile of $\mathrm{TiF}^{+}$in the titanium alloy: (a) MCP treated, (b) untreated.
$\mathrm{MCP}$ 処理に伴う表面の状態変化を調べ，表面に形成される 酸化膜のキャラクタリゼーションを行った.

（1）未処理品, MCP 処理品の表面粗さはそれぞれ Ra 100 $\mathrm{nm}, \mathrm{Ra} 1 \mathrm{~nm}$ 程度であり, ミクロ的な凹凸に違いが見ら れたが，表面粗さによる表面積の増加は僅かであった。

(2) 未処理品, MCP 処理品ともに表面には有機物污染と 考えられるCが検出され, 表面のチタンは酸化された 状態であることが分かった。 また, 試料表面にはチタン の結晶粒子の配向が認められた.

(3) 断面 TEM 観察より, 未処理品, MCP 処理品ともに 表面には非晶質のチタン酸化膜が認められ，その厚さは $\mathrm{MCP}$ 処理品で約 $5 \mathrm{~nm}$, 未処理品で約 $8 \mathrm{~nm}$ と観察され た。

（4） SIMS 分析より，水素は未処理品の方が内部側で多く 存在して抢り，水素のマッピングより，粒界程度の大き さの偏析が認められた. チタン材料内での水素の挙動は 粒子の結晶方位に強く影響されるものと考えられた.

（5） TOF-SIMS 分析より, MCP 処理品では表面層と基 板との界面近傍で $\mathrm{H}^{+}$と $\mathrm{TiF}^{+}$に極大分布が見られ， $\mathrm{MCP}$ 処理で界面層に水素を含む化合物や欠陥の形成が 考えられた．この界面層にはチタンとフッ素が結合した 成分の存在が示唆された。この界面層は MCP 処理品に 特徵的に認められた。

\section{〔文献〕}

1) M. Minato and Y. Itoh: J. Vac. Sci. Technol., A13 (1995) L10.

2) 森本佳秀, 竹村 厚, 室尾洋二, 魚田雅彦, 佐藤吉博, 斉藤芳 男 : 真空, 45 (2002) 665.

3) H. Kurisu, T. Muranaka, N. Wada, S. Yamamoto, M. Matsuura and M. Hesaka: J. Vac. Sci. Technol., A21 (2003) L10.

4) 栗巣普揮, 山本節夫, 松浦 満, 部坂正樹: 電子材料 9 月号 (2005) 26.

5）伊藤好男, 湊 道男 : 真空, 40 (1997) 248.

6) Y.Strasser: Shinku, 12 (1969) 389. 